\title{
The Historical Dynamics of Resource Frontiers
}

Per Högselius

Megan Black 2018. The Global Interior. Mineral Frontiers and American Power. Cambridge, MA: Harvard University Press, geb., 348 S., US\$ 39.95, ISBN: 978-0-674-98425-7.

Judd C. Kinzley 2018. Natural Resources and the New Frontier. Constructing Modern China's Borderlands. Chicago: University of Chicago Press, brosch., 234 S., US\$ 35.00, ISBN: 978-0-226-49229-2.

Felix Rehschuh 2018. Aufstieg zur Energiemacht. Der sowjetische Weg ins Erdölzeitalter, 1930er bis 1950er Jahre. Osteuropa in Geschichte und Gegenwart, Band 1. Köln: Böhlau Verlag, geb., 373 S., $€$ 39,99, ISBN: 978-3-412-51132-6.

Corey Ross 2017. Ecology and Power in the Age of Empire. Europe and the Transformation of the Tropical World. Oxford: Oxford University Press, geb., 477 S., f 47.49, ISBN: 978-0-19-959041-4.

In 2012 the American author Michael Klare published a book with the provocative title The Race for What's Left: The Global Scramble for the World's Last Resources. The book painted a gloomy picture of the world's future resource supply, pointing to a relentlessly growing scarcity of practically all natural resources and raw materials. He argued that the world's great powers are now set on a path to a last epic struggle against each other for access to and control over those few noteworthy mineral and other resource deposits that still await exploitation. While the more easily accessible resource riches have already been exhausted, or so Klare's argument goes, human resource needs continue to grow at a rapid pace from day to day, and so the world's industrial nations have no choice but 
to target much less attractive deposits. These are typically environmentally risky, technologically difficult and economically expensive to extract (Klare 2012). Klare's book built on and further contributed to a popular narrative, much publicized and circulated in popular media in the early twenty-first century, focussing on the world's "last resource frontiers", to which resource explorers are now inexorably pushed. These are located in areas such as the Polar regions and the deep sea; in strange geological formations like Canada's tar sands and, not least, in war-torn countries such as Afghanistan and the Democratic Republic of the Congo, whose internal turmoils have so far prevented resource extraction from being scaled up.

Klare's book might have fitted well as an epilogue to the economist Edward Barbier's more academic book Scarcity and Frontiers: How Economies Have Developed Through Natural Resource Exploitation, which was published at about the same time. Barbier hypothesizes that human history and humanity's evolutionary path from hunters and gatherers via the agricultural transition towards modern industrial civilization has always hinged on the identification and exploitation of natural resources in new frontier regions. The goal has been to banish the recurring spectre of scarcity, which has haunted human societies for millennia. It was the quest for scarce food supplies in times of steady population growth that drove humans to successively expand their agricultural frontiers during the Neolithic era, continuously cultivating more and more fertile land while clearing forests; it was the dream of striking it rich in Australian gold and wool that laid the foundation for seriously breaking into that continent; it was the quest for Siberian natural resources that drove Russian ambitions to settle those eastern territories; and so on (Barbier 2011).

There is something undeniably attractive in looking at the history of natural resource extraction through the lens of "frontiers", no matter whether the term is explicitly used or not in the analysis. Obviously this cannot be the sole conceptual lens used for studying extractive industries, and a critical voice might easily disregard any frontier narrative as overly simplified and too structure-oriented (at the expense of a more actor-oriented lens). However, neither sweeping academic works like Barbier's nor popular ones like Klare's are well suited as access points into more complex debates on the history of natural resource extraction. Luckily, recent years have seen a surge of much more profound empirical research into the historical dynamics of resource frontiers. A range of new books and $\mathrm{PhD}$ dissertations are currently being published on the topic, going into much greater depths and approaching the phenomenon from a healthy diversity of geographical, temporal and disciplinary perspectives. It is an exciting new field in the making, in which the history of science and technology interacts in 
often surprising new ways with environmental history, political geography, economic history, anthropology, (post-)colonial studies, various "area studies", just to mention a few. Many of these top quality historical books convincingly point to a messy, often hopeless complexity in the making of resource frontiers.

\section{Resource Frontiers in the Making: Variations on a Global Theme}

Take Megan Black's The Global Interior, which narrates the US Interior Department's evolution from its formation in 1849 up to today. While in most countries the Ministry of the Interior is the office in charge of ensuring matters such as national security, immigration and public administration this is different in the United States, where its primary function has always been promoting and regulating natural resource extraction. Among other things, the United States Department of the Interior (DOI) comprises the US Geological Survey. The DOI was set up in response to what was perceived as a much too chaotic and unruly expansion of US settler colonialism westwards in the mid-nineteenth century. It assumed the task of bringing order to a range of areas from agricultural reclamation and hunting practices to forest clearances and the frenzy of gold and oil rushes. The vast new territories that were acquired in the West, especially as a result of the Mexican-American War (1846-1848), were in essence viewed as foreign lands, and it was the DOI's task to oversee the process by which they were materially integrated with the rest of the nation. Natural resources played a critical role in this context, as their lure attracted new settlers from the East. The DOI actively promoted resource extraction in the frontier regions. Strikingly, however, it also came to play a leading role in conservation, namely by regulating and restricting resource extraction in the context of negotiations with Native Americans and in the quest for national parks. Later on-and long after the formal closing of the North American frontier in 1890 - the DOI continued to play similar roles abroad by becoming deeply involved in US formal and informal empire-building, promoting and regulating resource extraction in Alaska, Puerto Rico, Cuba, the Philippines, the Pacific, South America and the Middle East. There, the DOI was usually perceived-and also regarded itself-as the "soft" arm of American imperialism, promoting friendship, peace, development and environmental protection. It sought to build and profit from fruitful relations with powerful American extractive companies as well as with local rulers and organizations, while its interests often clashed with those of the US military-the "hard" arm of American empire. The DOI eventually ex- 
tended its foreign-imperial role even more by becoming a key promoter and regulator of resource extraction in the deep seas-and eventually on the Moon. Its far-reaching activities-and power-in the field of conservation and environmental protection, however, were troubled by events such as the 1969 oil spill tragedy off the Californian coast, which paved the way for new, competing agencies like the US Environmental Protection Agency set up in 1970 .

Judd Kinzley's Natural Resources and the New Frontier is another impressive work in the same vein. It seeks to sort out the role of natural resource extraction in the making of Xinjiang as a Chinese frontier province and its incorporation into the Chinese state. It starts out with the Qing conquest of this huge, Moslem-Turkic region in Asia's interior in 1759 and the initial attempts to stabilize imperial control over it by bringing in Han settlers and soldiers. These early efforts centred on reclaiming new agricultural land through conversion of the vast grasslands that make up most of northern Xinjiang, thus extending the Chinese agricultural frontier to this remote frontier region. However, Turkic uprisings in the region thwarted these attempts, especially in the $1860 \mathrm{~s}$, and caused thousands of Han settlers to flee back to what Kinzley calls "China-proper". Hence the frontier (area) became largely abandoned. When attempting to recover from the turmoil, Xinjiang's local officials discovered that the Qing government in Beijing was less and less able to sustain its earlier financial assistance to the frontier region in the West due to conflicts and war threats from Europe and Japan as well as a gradual political and economic downturn. Local Han officials sought to cope with the drying up of funds required for supporting Xinjiang's bureaucracy and army by extracting and exporting local natural resources to Imperial Russia, which in the late nineteenth century firmly established a new colonial frontier in Central Asia. Initially furs, pelts and wool figured among the favourite commodities of this cross-border trade, but were soon followed by modern fuel resources-oil in particular-and precious and industrial minerals such as gold, tungsten, lithium and beryllium. Thus the Russian Central Asian resource frontier actually moved across the Chinese border into Xinjiang. Russia established an informal empire in Xinjiang, taking control of virtually any extractive activity that was technologically or organizationally demanding, while absorbing all production. In return, the Russians provided Xinjiang's Han provincial government with technical expertise and military protection in face of local Muslim rebellions. When the newly established People's Republic of China finally incorporated the frontier province more firmly into its territory, Xinjiang continued to export its raw materials to the Soviet Union. This practice was maintained until the 1960 Sino-Soviet split changed the material flows, causing them to move rather East than West, that is from 
Xinjiang to Beijing and the coastal regions of Eastern China. Hence the making of Xinjiang as a resource-based frontier region was anything but a linear process.

Xinjiang's dependence on advanced Russian and Soviet technology may seem ironic in view of the Soviet Union's own problematic dependence on European and American technology for extracting, refining, storing and transporting the vast resource riches that awaited exploitation on Imperial Russian and later Soviet territory. This technological dependence forms one of the main themes in Felix Rehschuh's Aufstieg zur Energiemacht, in which petroleum is the focal resource. Rehschuh uses extensive Russian archival sources to map the Soviet Union's early attempts to harness its oil resources. The book starts out by reminding the reader that Imperial Russia was already a leading global oil power. The oil came from the fabulously rich fields in the Baku area in what is now Azerbaijan, at that time a colonial Russian periphery. After the Bolshevik revolution, however, the new Soviet leaders viewed petroleum as a "typically capitalist" fuel and actively promoted "more socialist" forms of energy like coal, hydropower and electricity. Technological stagnation and lack of investment early on led to a situation of looming petroleum scarcity. The country's internal oil frontier stopped advancing in both vertical and horizontal terms: the Soviets were unable to carry out deeper drillings in the old oil regions, yet the search for new oil frontiers further east was half-hearted at best. By the 1930s, Soviet geologists thought it probable that a vast area between the Volga River and the Urals was immensely rich in oil. This would prove to be true and the region was subsequently dubbed the "Second Baku". However, as Stalin's Great Terror set in, no leading geologists or oil experts were willing to spearhead the intrinsically risky project of seriously developing this new oil province. It was not until the eve of Hitler's invasion of the Soviet Union in 1941 that investments finally took off, but by then it was too late for the new resource frontier to rescue the Red Army by providing the much needed oil. Paradoxically during the following period the Soviet Union became import-dependent on oil, as its military airplanes were fuelled by refined oil products from the United States. Meanwhile Soviet petroleum geologists and engineers sought to deal with its resource scarcity by developing alternative resource frontiers, pushing exploration in northern Iran-which failed-and, following the Red Army's liberation of East-Central Europe, in Romania, Austria and Hungary. In the immediate post-war period, the latter regions contributed substantially to Soviet success in coping with internal petroleum shortages. In terms of domestic oil sources, the Caucasus, surprisingly, continued to be considered as the main production basis well into the late 1940s. Only when the fields around Baku showed unequivocal signs of depletion did the Soviets finally change 
their stance and fully acknowledged the centrality of the Volga-Urals region for future oil supplies. From the mid-1950s on, production from the immensely rich fields there even allowed the Soviet Union to (re)emerge as an oil exporter and a global oil power. A "Third Baku" subsequently emerged in north-western Siberia.

The fourth relevant work is Corey Ross's Ecology and Power in the Age of Empire. Ross's core interest is in the environmental consequences of European resource extraction in the tropical world. The findings are perhaps not that surprising - the main conclusion being that European imperialism caused far-reaching environmental destruction in the tropics from the midnineteenth century onwards-but the minute detail with which the author uncovers the scope and scale of the disaster is impressive and shocking. Ross further balances this sad story by offering a likewise detailed account of the efforts to cope with environmental problems in the colonies. Like Black and Kinzley, Ross makes ample use of "frontier" terminology, the most important frontiers in his case being situated in sub-Saharan Africa and Southeast Asia. Targeting the era from 1870 to "the end of the colonial era", that is the early 1960s, Ross picks a number of key resources and commodities for analysis, starting with biological ones like cotton, cocoa and rubber, before turning to mineral resources: tin, copper and oil. The reader is familiarized with a wide range of extractive companies of very different types, along with state actors at various levels and serving several different imperial powers: Britain, France, Germany, Belgium and the Netherlands. But Ross also takes indigenous agency seriously, studying the relationships-sometimes cooperative, sometimes competitive, at times confrontational-between European actors and local rulers, smallholders, labourers and commercial players. The actor landscape is further complicated by the substantial roles assumed, for example, by Chinese entrepreneurs and merchants in the Southeast Asian tin and rubber industry, the influx of Indians into the same region and complex migration flows that the massive investments in Central African copper mining set in motion in the early twentieth century.

The books by Black, Kinzley and Rehschuh all take the form of indepth historical case studies, primarily based on archival finds, whereas Ross's book is much more synthetic in style and relies more on secondary literature and other published sources. Kinzley and Rehschuh share an interest in resource frontiers in specific geographical regions, while Black opts to tell her story through the lens of a particular organization, which takes her to unexpected places. Though the time periods in each book are different, the four authors ambitiously cover surprisingly long time perspectives-arguably a necessary strategy for anyone who wants to trace the making of resource frontiers, since these do not come into being overnight. 
Interestingly, none of the authors seem to define themselves as historians of science or technology-and yet, as discussed in the following, they all deliver crucial new insights to our field.

\section{Frontier-actor-networks and Clashes Between Extractive- technological Cultures}

One of the great benefits of diving into the works discussed here is that they take into account a vast and colourful cast of characters. Barbier's Scarcity and Frontier, which hardly mentions any people or organizations at all in its all-structural analysis, and Klare's The Race for What's Left, which mainly looks at a few governments and large extractive companies, appear pale and life-less by contrast. Black, Kinzley, Rehschuh and Ross all track a mesmerizing plethora of people and organizations that over the years pushed-and sometimes withdrew from-one or the other resource frontier, shaping world resource history in the process. The actor networks are not merely "multi-layered", as Kinzley suggests, but also often surprising and paradoxical, as in the case of the DOI, originally set up to handle "internal" US issues, before becoming one of the leading actors and promoters of US imperial expansion abroad. Or Xinjiang's provincial Han officials, who, while passionately claiming a nationalist affiliation to China, cut their links to Beijing in order to work closely with Russian diplomats, merchants, engineers and scientists. Rehschuh, for his part, makes ample use of personal quotes from Stalin and other leading Bolsheviks, thus immediately allowing the reader to experience the first radical, euphoric and subsequently desperate and frightening atmosphere that characterized the world of oil extraction in the early Soviet decades. But state and commercial actors are not the only players that figure prominently. Scientists, engineers and other technical experts are omnipresent. In Black's account they are the ones who make it "natural" for the DOI to go global: the experience gained by DOI experts from promoting and regulating the internal frontier in the United States itself was gradually put to work for similar tasks abroad. In no other office of the US state bureaucracy did a corresponding scientifictechnical expertise exist. In the same vein, it was natural for Russian geologists and engineers in Kinzley's narrative to move across the RussianChinese border, making use of their Soviet Central Asian experience for the purpose of geological survey in Xinjiang.

Of the books reviewed here, Ross's Ecology and Power goes furthest in pinpointing the role of scientists and engineers in pushing and shaping global resource frontiers. Ross shows in great empirical detail how $\mathrm{Eu}-$ 
ropean scientific and technological methods became an integral part not only of actual resource exploration and extraction, but also of justifying colonial rule over much of the tropical world from the late nineteenth to the mid-twentieth century. European experts, arriving in the tropics with a modern scientific-technical mind-set, were shocked to find the natural resources of these foreign lands being exploited in "inefficient" and "primitive" ways. They were also appalled by the existence of immense resource riches that in some cases were well-known but, even so, had not actually been taken into use. A state of affairs the European engineers felt compelled to change by setting up vast extractive projects-and providing the tropics with Western "civilization" in the process.

Likewise Megan Black repeatedly points out the inclination of US scientists and engineers to perceive foreign territories as resource "wastelands", which the indigenous populations failed to put into production. For the self-proclaimed "civilized" North Americans it was morally imperative to rectify this by launching large-scale exploitative ventures in places like Puerto Rico, Cuba, Alaska and the Philippines. Developing the concept of "resource primitivism", Black analyses the Western penchant for disregarding the legacy of traditional, indigenous extractive practices and techniques, either on the basis that they were actually inefficient or, more strikingly, that they were allegedly not "modern" or "rational" enough. Here we find one of the most intriguing issues from a historico-technological point of view when it comes to resource frontiers: the clash between totally different technological cultures. Ross, in his book, further problematizes resource primitivism by conclusively depicting how Western scientists and engineers underestimated over and over again the power of indigenous knowledge throughout the colonial tropics, while simultaneously overestimating their own capabilities in applying Western techniques and practices to resource extraction in the Global South-often with tragic outcomes in terms of vast environmental destruction and loss of human lives due to diseases and starvation. He provides several revealing cases of indigenous knowledge and practices successfully bouncing back, as in the case of Southeast Asian rubber or African cocoa, where traditional, small-scale methods of cultivation were able to out-compete "modern" Western extraction-much to the surprise of the Europeans. The tension between traditional and modern technical practices is also a key issue in Kinzley's Xinjiang narrative, even if the context here is quite different. Since lack of funds made large-scale investments in modern industrial resource extraction practically impossible, Xinjiang's local rulers responded by instituting an extractive regime-most prominently so in gold mining on the slopes of the Kunlun mountains in southern Xinjiang-based on local labourers digging out gold-bearing rocks by hand. The workers were not paid any 
wages but were obliged to sell their gold to the local authorities. Thus the latter hoped to raise funding for their army and administration given their failure to build-up a tax-payer basis, which they had tried to do by settling Han farmers in new agricultural reclamation areas. Such cases vividly illustrate how technological choices and competition between radically different technological paths were unpredictable.

\section{The Critical Role of Infrastructures in Shaping Resource Frontiers}

On the surface resource extraction might appear as something that takes place in clearly defined spots and spaces, that is, distinct geographical areas that can be neatly marked out on a map: an oil-field, a copper mine, a cotton plantation, etc. The books discussed here, however, make clear that actual resource spaces are much larger. This is, to start with, due to the fact that extraction is only the first step in turning a natural resource into something useful. Usually it has to be refined or converted in one way or another and transported over long distances-typically requiring more or less complex technological solutions-before it reaches the market. In resource frontier regions in particular the need for new transport infrastructure becomes very pressing. As a matter of fact, it is the main reason why large-scale resource extraction in frontier regions did not seriously bet cracking before the second half of the nineteenth century, when new transport systems in the form of steamships, railways, improved waterways and eventually pipelines, oil tanker and powerful trucks entered the scene.

In many places the new roads, railways and ports built to cope with resource flows came to define significant infrastructural landscapes not only for the resource industries as such, but for the frontier regions at large. Following, for example, Christopher Jones's excellent book Routes of Power (2014), Kinzley shows how the Russian-funded infrastructural projects for the purpose of moving raw materials within and beyond Xinjiang formed the basis for the region's transport modernization in general. Hence until the 1960s Xinjiang was far better connected with the Soviet Union than with China-proper in terms of transport, despite being always politically recognized as a Chinese province. Likewise the Soviet "Second Baku" in Rehschuh's account was a vast infrastructural undertaking, with oil explorers in Bashkiria and Tatarstan starting their work in places where "neither roads nor rails" (Rehschuh 2018: 243) existed. The quest for oil made it imperative to create the basic infrastructure, which was subsequently followed up by vast pipeline networks. These frontier infrastructures played a critical role in materially-and symbolically-incorporating them into the national 
territory. Ross, too, refers to the trend of resource extraction for stimulating a flurry of infrastructure projects. The "imperial tin frontier", for example, "played a central role in the construction of modern infrastructure across large part of the [Southeast Asian] region, from railways and roads to dams and waterworks" (Ross 2017: 160). The regions affected by the extractive frontier increased further in size due to the emerging variety of supporting industries in the wider region as well as the obvious large-scale environmental destruction far beyond the extractive sites as such-whether we look at deforestation in the Central African copper mining regions or pollution of rivers far downstream from Malayan tin mining sites.

\section{Resource Frontiers and Imperialism}

In terms of political history it is striking how often and intimately the attempts to push new resource frontiers have been linked to formal and informal imperialism or colonialism. It is almost as if imperialism and resource frontiers were intrinsically part of one and the same phenomenon. Ross, Kinzley and Black are all very explicit about the fact that by scrutinizing the history of resource frontiers they are actually also studying processes of colonization and empire-building. Rehschuh could potentially have made the same argument, although Soviet dominance of oil-rich regions like Azerbaijan, Kazakhstan, Tatarstan and Bashkiria constitutes a case of what authors such as Alexander Etkind (2011) have called "internal" rather than "external" colonization.

As far as external colonies are concerned, there are two variants: one formal and the other informal. Regarding resource frontiers and formal empires, Ross and Black, as already mentioned above, point to the ways in which extractive activities in contested regions were actively mobilized by foreign policy actors for cementing political and military authority over a certain region. But the more interesting argument is perhaps related to informal imperialism. Kinzley, for example, argues that "Soviet officials effectively transformed Xinjiang into a nearly textbook example of 'informal empire"'. It is interesting that seemingly the Soviet Union never had plans to annex Xinjiang, but rather preferred to keep it at an arm's length, politically speaking. Thus, Moscow did not have to bother with any greater responsibilities for the region's development and its population, while still retaining full access to its resource riches. Black points to a quite similar history in the case of the US hegemony over Latin American resource frontiers. Needless to say, the issue of informal imperialism-or "neo-colonialism", as Sartre called it-has continued to be vividly discussed in resource 
extraction in the aftermath of formal decolonization in Africa, Asia and the Caribbean. Social scientists, especially in fields such as geography and political ecology, continue to research such trends as they evolve in our own time.

Another striking feature in this literature is that resource frontiers almost inevitably seem to be linked to the perception of some natural resources as "strategic". Megan Black, for example, shows how the United States, in the run-up to World War II, came to interpret certain resource finds in Alaska and the Philippines-chromium, tin and platinum in particular-"as being vital to conducting war", which led directly to substantially increased funding for the DOI (cf. Ingulstad 2015). These funds became instrumental in further pushing (North) American resource frontiers. In the Soviet Union, meanwhile, World War II signalled a radical shift in the perception of oil from a fuel that did not really fit socialism to a strategic, militarily vital resource, abundant access to which made the difference between life and death for an entire nation. The belated decision to invest in new oil frontiers further East was a direct consequence of this paradigm shift. Kinzley notes that the Soviet Union also considered Xinjiang's resources as being of strategic significance. This applied in specific to various rare minerals (such as tungsten, lithium, tantalum, beryllium), known to exist in the province's north-western periphery, which were needed for various military machinery and equipment, including nuclear weapons. The perceived strategic nature of these resources became the main driving force for the Soviet Union to push the Soviet Central Asian resource frontier across the border into Chinese territory. Ross offers a range of similar examples from the tropical world. Black, however, aptly reminds us that resources are never strategic in any objective sense; in fact, they become strategic through social processes, as some actors deliberately seek to frame one or the other resource or commodity as being particularly important for the nation while seeking additional funds for themselves (cf. Vikström 2016).

Sometimes the notion of resource frontiers may lead us to think of extractive activities as advancing more or less autonomously, especially in the context of non-renewable resources, as mining companies and other actors continuously look for new deposits to be exploited while old ones are depleted. In geographical terms, however, it is in no way given where tomorrow's extractive activities will take place. In the United States, the DOI moved for a long time relentlessly from one part of the world to the next, promoting in particular US-led resource exploitation in the Global South. But when local opposition to European imperialism mounted in the Interwar period and, even more so, after World War II, the DOI increasingly feared that US extractive activities in the Global South would 
be associated with the obscure European projects. Black argues that in this situation the DOI deliberately sought to retreat from the world arena. It changed direction, and increasingly started to focus on a totally different kind of frontier: the offshore oil and minerals frontier. In the following, the US claimed a vast new submerged territory on its continental shelf, triggering the intense exploration and exploitation of subsea resources (cf. Sparenberg 2019). The quest for mineral resources in outer space can be considered in the same way: there, the geologists and extractive companies would not have to deal with any problematic indigenous populations. Kinzley, in turn, stresses that the Soviet Union did not take any interest in Xinjiang per se; it rather targeted certain very specific frontiers, while neglecting others, which led to Xinjiang's resource frontiers being heavily concentrated in the north-western part of the province. The overall picture becomes one of unpredictable resource geographies.

\section{What Next?}

The four books discussed in this review article are all impressive, meticulously researched academic works. It should perhaps be mentioned that Felix Rehschuh's book is nothing less than his $\mathrm{PhD}$ thesis, and that Megan Black's and Judd Kinzley's works are similarly, following the American academic tradition, reworked versions of their $\mathrm{PhD}$ manuscripts. All of them, and this goes for Corey Ross's book, too, have been in the making for at least five and often rather ten years. This gives an idea of the immense challenge of researching resource frontiers from an historical point of view. A particular challenge is clearly the transnational nature of most resource frontiers, which calls for in-depth knowledge of several different national and regional contexts while requiring empirical sources from different countries and in different languages. Ross, while not going into the archives, makes systematic use of books, journals and reports in English, French, German and Dutch language, while Kinzley relies on a plethora of Chinese, Taiwanese and Russian archival sources. Rehschuh skilfully navigates all the main Russian archives. Yet it is perhaps surprising that the authors, with Kinzley as the exception, do not really make use of archival sources from further countries to a greater extent than they do, and that they do not cooperate more with scholars from the studied regions. Preferences in this respect may be rooted in pragmatic considerations, including research funding. But for the future, a more systematic collective-transnational methodological approach would clearly be worthwhile trying out. This would require a different academic work mode, with much more 
substantive co-authoring of articles and books-something that historians have generally been bad at!- - and the sharing and joint analysis of archival finds from different countries and regions. Luckily promising activities are already on their way here, with at least two European research networks currently enjoying generous funding, the purpose of which is precisely to bring together scholars from different regions with different language skills in the study of resource frontiers and more generally the historical shaping of resource extraction. ${ }^{1}$ Ideally, this could be the beginning of a broader transformation of our research practices.

Moreover, while the study of resource frontiers thus confirms the need for the ongoing "transnational turn" in the history of science and technology, it also points to a need for leaving our intellectual comfort zones and merge our interests as historians of science and technology with those of other academic fields. In particular, the study of natural resources lends itself in a natural way to integrating studies of the past with studies of the present. This translates into a great potential for cooperation with not only, say, environmental historians, but with students of resource geopolitics, cultural studies, environmental justice, resistance movements, and so on. It is impossible to discuss the historical dynamics of resource frontiers without taking into account radical events and trends in our own time, from the recent fuss over US President Trump's alleged desire to "buy Greenland" to the escalating deforestation disaster in Amazonia and, of course, the climate crisis. Never before has there been such an urgent need for historians of technology to contribute to the debate about-and the shaping of-our common future, and we cannot do this without challenging the boundaries of our own academic field.

Funding Open access funding provided by Royal Institute of Technology.

Open Access This article is licensed under a Creative Commons Attribution 4.0 International License, which permits use, sharing, adaptation, distribution and reproduction in any medium or format, as long as you give appropriate credit to the original author(s) and the source, provide a link to the Creative Commons licence, and indicate if changes were made. The images or other third party material in this article are included in the article's Creative Commons licence, unless indicated otherwise in a credit line to the material. If material is not included in the article's Creative Commons licence and your intended use is not permitted by statutory regulation or exceeds the permitted use, you will need to obtain permission directly from the copyright holder. To view a copy of this licence, visit http://creativecommons. org/licenses/by/4.0/. 


\section{Endnotes}

1 These networks are called "Challenging Europe: Technology, Environment and the Quest for Resource Security” (EurReS, led by Matthias Heymann, Århus University) and "Global Resources and Sustainability of European Modernization, 1820-2020" (GREASE, coordinated by Erik van der Vleuten, Eindhoven University of Technology).

\section{References}

Barbier, Edward B. 2011. Scarcity and Frontiers: How Economies Have Developed Through Natural Resource Exploitation. Cambridge: Cambridge University Press.

Etkind, Alexander 2011. Internal Colonization: Russia's Imperial Experience. Cambridge: Polity Press.

Ingulstad, Mats 2015. The Interdependent Hegemon: The United States and the Quest for Strategic Raw Materials during the Early Cold War. The International History Review (37): 59-79.

Jones, Christopher F. 2014. Routes of Power: Energy and Modern America. Cambridge, MA: Harvard University Press.

Klare, Michael T. 2012. The Race for What's Left: The Global Scramble for the World's Last Resources. New York: Picador.

Sparenberg, Ole 2019. A Historical Perspective on Deep-Sea Mining for Manganese Nodules, 1965-2019. The Extractive Industries and Society. https://doi.org/10.1016/j.exis. 2019.04.001

Vikström, Hanna 2016. A Scarce Resource? The Debate on Metals in Sweden 1870-1918. The Extractive Industries and Society. https://doi.org/10.1016/j.exis.2016.03.009

Publisher's Note Springer Nature remains neutral with regard to jurisdictional claims in published maps and institutional affiliations.

Per Högselius

History of Science, Technology and Environment

KTH Royal Institute of Technology

Teknikringen 74D

100 44 Stockholm

Sweden

perho@kth.se 